\title{
INTELIGÊNCIA SOCIAL: DISCUSSÃO ACERCA DA POSSIBILIDADE DE UM MODELO PARA O SECRETARIADO EXECUTIVO
}

\section{SOCIAL INTELLIGENCE: DISCUSSION ABOUT THE POSSIBILITY OF A MODEL FOR THE EXECUTIVE SECRETARIAT AREA}

Mônica Luísa Tremarin de Andrade

Bacharel em Secretariado Executivo pela Universidade Federal de Santa Catarina - UFSC E-mail: monicatremarin@uol.com.br (Brasil)

\section{Susana Borneo Funck}

Doutora em Humanidades pela Universidade do Texas em Arlington.

Professora de literaturas de língua inglesa na Universidade Federal de Santa Catarina - UFSC E-mail: sbfunck@floripa.com.br (Brasil) 


\title{
INTELIGÊNCIA SOCIAL: DISCUSSÃO ACERCA DA POSSIBILIDADE DE UM MODELO PARA O SECRETARIADO EXECUTIVO
}

\section{RESUMO}

A capacidade de se relacionar com as pessoas é cada vez mais apontada como fator de sucesso, tanto na vida pessoal como na profissional. Como forma de aprofundar-se nesta capacidade, a inteligência social busca maior compreensão para o desenvolvimento das habilidades de relacionamento. Este estudo tem o objetivo de compreender o conceito da inteligência social e relacioná-lo à realidade e às competências do profissional de secretariado por meio da exposição dos pressupostos do modelo de inteligência social de Daniel Goleman. Para isso, foi realizada uma pesquisa exploratória referente à inteligência social e ao secretariado com informações presentes na literatura, e uma pesquisa de campo, com a aplicação de um questionário a uma secretária executiva sobre a relevância dos aspectos do modelo de Goleman, a partir de sua experiência profissional. Por meio dessa exposição foi possível discutir a possibilidade de elaboração de um modelo de inteligência social direcionado ao Secretariado Executivo, de modo a contribuir para o aprimoramento das habilidades de relacionamento esperadas do secretário executivo e identificá-la como uma competência a ser agregada ao perfil deste profissional.

Palavras-chave: Inteligência Social; Secretariado Executivo; Relações Humanas.

\section{SOCIAL INTELLIGENCE: DISCUSSION ABOUT THE POSSIBILITY OF A MODEL FOR THE EXECUTIVE SECRETARIAT AREA}

\begin{abstract}
The ability to relate to people has been pointed out as a success factor, both in personal and professional life. In a way to deepen this ability, social intelligence searches greater understanding of relationship skills' development. This study seeks to investigate the concept of social intelligence and relate it to the executive secretary's reality and competences through the exposition of Daniel Goleman's social intelligence model. It was carried out an exploratory research with information based on social intelligence and secretarial literature, and fieldwork, with a questionnaire applied to an executive secretary about the relevance of these aspects based on her professional experience. Through this exposition, it was possible to discuss the possibility of creating a model of social intelligence directed to executive secretariat, contributing to the upgrading of the relational skills expected from the executive secretary and identifying it as a competence to be added to this professional's profile.
\end{abstract}

Keywords: Social Intelligence; Executive Secretariat; Human Relationships.

Revista de Gestão e Secretariado - GeSec, São Paulo, v. 5, n. 2, p 23-48, mai./ago. 2014. 


\section{INTRODUÇÃO}

A capacidade de se relacionar com as pessoas é cada vez mais apontada como fator de sucesso, tanto na vida pessoal como na profissional. Especificamente, no campo das profissões, as competências comportamentais, em muitos casos, são mais valorizadas ou tão valorizadas quanto as competências técnicas, em processos de seleção e para a permanência no mercado de trabalho.

Como forma de aprofundar o conhecimento e aprimorar essas habilidades, a inteligência social, conceito que começou a ser estudado por pesquisadores e teóricos acadêmicos na década de 1920, procura mensurar a competência social do indivíduo: sua capacidade de lidar com outras pessoas e conseguir a cooperação delas (Albrecht, 2006).

Em ambientes organizacionais, o profissional de Secretariado Executivo possui contato direto com os diversos níveis hierárquicos; é o elo entre clientes internos e externos, parceiros e fornecedores; e atua ao lado de quem detém o poder decisório. A polivalência da profissão envolve não somente as técnicas secretariais, mas também as competências comportamentais e de relacionamento, pois como já foi mencionado, é inerente ao profissional a interação e parceria com os mais diversos personagens do ambiente organizacional.

Desse modo, julgou-se importante o estudo da inteligência social visando às relações no ambiente profissional e, especificamente, à profissão de Secretário Executivo, reconhecido como um agente facilitador entre a alta administração, os demais funcionários e clientes e externos.

Partindo do pressuposto de que é possível ser inteligente em relação ao mundo social, o presente estudo tem o intuito de compreender o conceito da inteligência social e identificá-la como uma competência a ser agregada ao perfil do profissional de Secretariado Executivo. Mais precisamente, busca-se responder ao seguinte questionamento: "os pressupostos do modelo de inteligência social de Daniel Goleman demonstram-se compatíveis para promover o desenvolvimento e aprimoramento das competências comportamentais e de relacionamento do Secretário Executivo?".

Com o intuito de focalizar os esforços de pesquisa e direcionar as respectivas atividades, delimitaram-se os seguintes objetivos específicos: a) evidenciar as principais caracterísitcas da inteligência social; b) verificar a adequação dos pressupostos do modelo de inteligência social de Daniel Goleman em relação às competências secretariais, a partir de informações presentes na literatura do secretariado e de um questionário de questões abertas aplicado a uma secretária

Revista de Gestão e Secretariado - GeSec, São Paulo, v. 5, n. 2, p 23-48, mai./ago. 2014. 
executiva; c) discutir a possibilidade de elaboração de um modelo de inteligência social para o Secretariado Executivo.

A fundamentação teórica baseia-se nos estudos de Daniel, Karl Albrecht e Tony Buzan a respeito da inteligência social, e de Medeiros \& Hernandes e Neiva \& D’Elia, no que diz respeito aos estudos da área secretarial. Como instrumento de técnica de pesquisa foi aplicado um questionário com questões abertas a uma secretária executiva da cidade de Florianópolis (SC), com mais de trinta anos de atuação na área. Os dados obtidos foram analisados sob os pressupostos do modelo de inteligência social proposto por Daniel Goleman.

Tendo em vista que o conceito de inteligência social é ainda pouco explorado e discutido no âmbito da formação acadêmica e profissional do Secretário Executivo, julga-se importante aprofundar os estudos desse conceito e relacioná-lo à realidade secretarial.

\section{REFERENCIAL TEÓRICO}

\subsection{INTELIGÊNCIA SOCIAL: CONSIDERAÇÕES BÁSICAS}

Nesta seção será realizada a revisão de literatura acerca da inteligência social, contextualizando, num primeiro momento, com os avanços da neurociência no campo social e, posteriormente, apresentando os conceitos dos principais autores da área.

\subsection{O CÉREBRO SOCIAL}

A neurociência social é um campo de exploração recente que tem como objetos de estudo o cérebro humano e as relações humanas. Suas descobertas revelam as funções de partes já conhecidas do cérebro em relação aos momentos de interação social e de que modo essas interações afetam biologicamente os envolvidos.

A partir de tais descobertas Daniel Goleman (2006) utiliza o termo cérebro social, ao constatar que "o próprio design do cérebro o torna sociável, inexoravelmente atraído para uma íntima ligação cérebro a cérebro sempre que nos entrosamos com outra pessoa." (Goleman, 2006, p. 5 , grifo no original). De acordo com o autor, o cérebro social não é formado por uma parte específica do cérebro, uma vez que todas as áreas participam de uma gama de funções, não existindo uma área exclusivamente social; na verdade, o termo corresponde às diversas partes Revista de Gestão e Secretariado - GeSec, São Paulo, v. 5, n. 2, p 23-48, mai./ago. 2014. 
ativas, abrangendo o cérebro como um todo, que orquestram as atividades quando as pessoas se relacionam entre si.

Figura1 - O cérebro social.

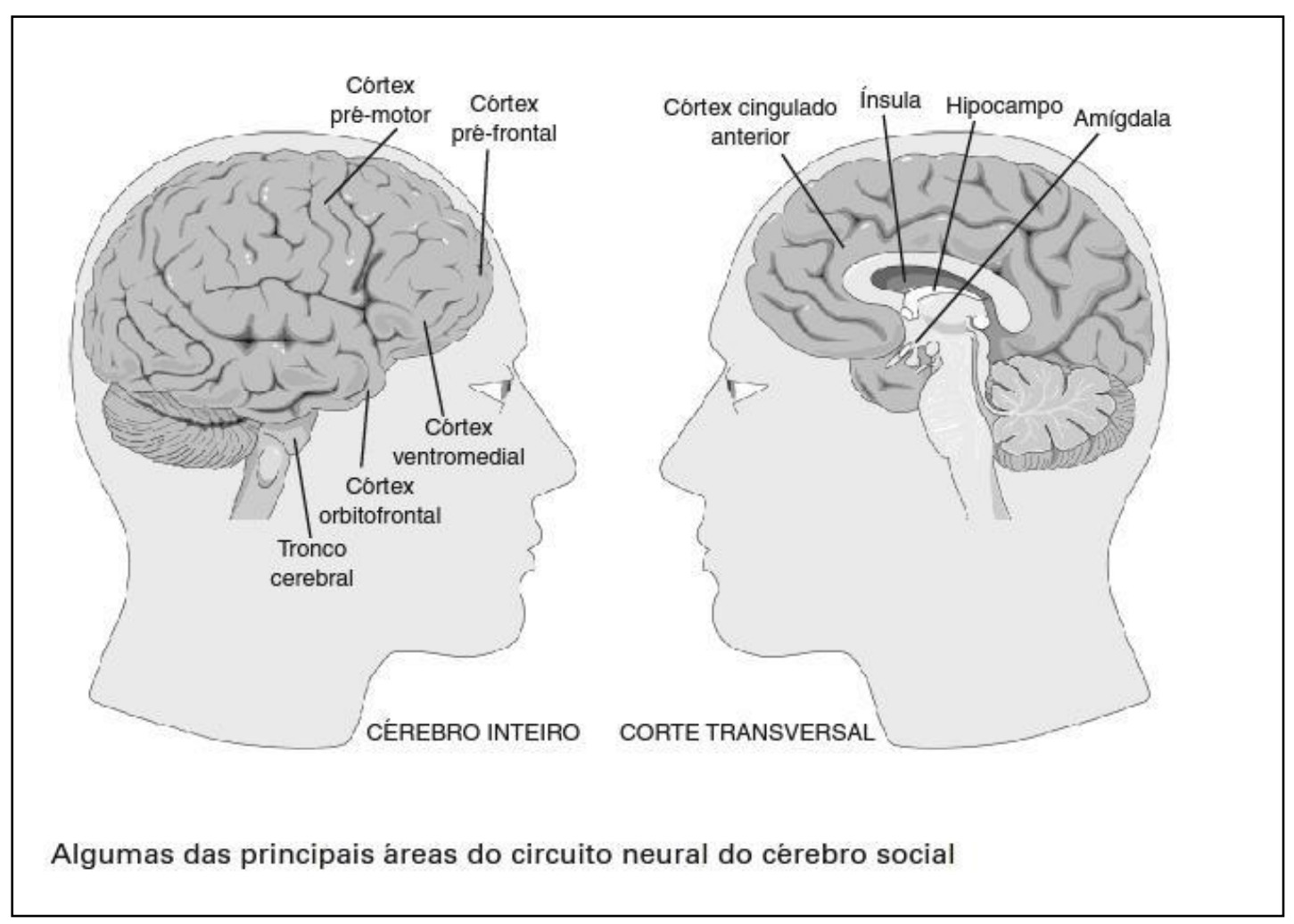

Fonte: Goleman (2006).

Para exemplificar algumas dessas descobertas, cita-se um tipo de neurônio observado pela equipe do neurocientista italiano Giacomo Rizzolatti, na década de 1990, que se mostrou ativo durante a execução de determinadas atividades e, também, durante a observação dessa mesma atividade em outra pessoa, denominado de "neurônio-espelho". Vários experimentos demonstram a relação dos neurônios-espelho com a execução-observação de ações: por exemplo, ao cheirar um líquido de odor desagradável, a parte anterior da ínsula é ativada e, graças às atividades dos neurônios-espelho, esta mesma estrutura (neste caso, a parte anterior da ínsula) reage em outra pessoa que observa a ação e quando visualiza a expressão de aversão (Goleman, 2006; Lameira et al., 2006).

A habilidade social depende dos neurônios-espelho, podendo ser considerada um

Revista de Gestão e Secretariado - GeSec, São Paulo, v. 5, n. 2, p 23-48, mai./ago. 2014. 
instantâneo neural da empatia em ação, pois eles permitem que o significado de uma ação seja compreendido automaticamente por meio da observação, tornando as emoções contagiosas e ajudando as pessoas a entrar em sincronia. Desse modo é possível entender a mente dos outros por simulação direta, na medida em que os mesmos sentimentos, movimentos, sensações e emoções também agem nas mesmas estruturas neurais da pessoa observadora (Goleman, 2006).

\subsection{RELACIONAMENTOS DE IMPACTO}

Ao longo da vida adulta os principais relacionamentos, de maior duração e intensidade, esculpem a forma, o tamanho e o número de neurônios e a propagação dos impulsos nervosos de uma célula nervosa a outra. Esta influência social deve-se à neuroplasticidade, capacidade do cérebro de modelar os circuitos neurais através da repetição de experiências. Assim, os relacionamentos ajudam a formar o cérebro guiando as conexões formadas pelos novos neurônios e determinando quais conexões serão preservadas. Neste caso, aplica-se o conceito do darwinismo neural: o que não é utilizado, atrofia (Goleman, 2006).

De acordo com Cacioppo e Decety (2011), uns dos primeiros divulgadores da neurociência social, o estado cerebral de uma pessoa influencia o de outra(s) através do que é expresso de modo verbal, não verbal ou comportamental. Isso ajuda a compreender a sensação de bem-estar quando se está junto de pessoas agradáveis, positivas e respeitosas, e os sentimentos de irritação e apatia em relação a pessoas que apresentam atitudes tóxicas, ou seja, que fazem os outros sentirem-se desvalorizados, intimidados, enfurecidos, frustrados ou culpados. Porém, mais do que estar consciente a respeito do contágio emocional que ocorre entre dois (ou mais) cérebros em interação, é importante atentar para os impactos que isso gera, biologicamente, nos envolvidos. Como afirma Goleman (2006, p. 260), “a maneira como um relacionamento afeta a nossa saúde dependerá da soma total de sua toxidade ou positividade ao longo dos meses e dos anos".

Durante as interações sociais, os sentimentos resultantes possuem consequências que se reproduzem no corpo humano, secretando hormônios que regulam os sistemas biológicos - do coração ao sistema imunológico. Com efeito, os relacionamentos moldam não somente a experiência e vida das pessoas, mas também a biologia dos seres humanos. Por exemplo, ao longo dos anos, os altos e baixos emocionais dos relacionamentos criam níveis de estresse que podem acelerar o surgimento de doenças ou agravar os sintomas daquelas já existentes. O cortisol, secretado pela glândula suprarrenal em momentos de estresse, é necessário em geral em níveis moderados; entretanto, se esses níveis ficarem elevados durante um período prolongado, o corpo

Revista de Gestão e Secretariado - GeSec, São Paulo, v. 5, n. 2, p 23-48, mai./ago. 2014. 
sofrerá as consequências: a secreção crônica de cortisol tem relação direta com as doenças cardiovasculares e os problemas de imunidade, aumentando também a diabetes e a hipertensão, e até mesmo destruindo neurônios no hipocampo e prejudicando a memória. Mais estudos neste sentido, como o do psicólogo Sheldon Cohen, da Universidade Carnegie Mellon, mostram que pessoas com menos relacionamentos e com redes sociais limitadas são mais vulneráveis ao vírus do resfriado comum (62\% ficaram resfriadas) do que as pessoas com maior contato social e maior diversidade na sua rede de relacionamentos (35\%). A imunidade mais elevada é atribuída ao fato de que círculos sociais diversos induzem a um sentimento de bem-estar que estimula a capacidade do sistema imunológico de atacar vírus invasores (Goleman, 2006; Buzan, 2005).

Diante do exposto a respeito das estruturas neurais, da capacidade de conexão cérebro a cérebro e do impacto que os sentimentos resultantes das relações causam na biologia dos seres humanos, constata-se a amplitude das conexões estabelecidas entre as pessoas. Desse modo, cabe a reflexão sobre a importância de estar consciente a respeito da influência, para o bem ou pra o mal, que os outros exercem, e igualmente, sobre a maneira como afetamos as pessoas integrantes do nosso círculo social. Direcionando essa reflexão para a atuação do secretário executivo, vale pensar sobre qual é marca que o profissional está deixando, se ela é positiva ou negativa, e de que maneira ele pode agir de modo a proporcionar estados benéficos nos outros. Em suma, por que não utilizar esse conhecimento para ser inteligente socialmente?

\subsection{OS PRIMEIROS ESTUDOS E OS CONCEITOS A RESPEITO DA INTELIGENCIA SOCIAL}

O termo "inteligência social” foi utilizado pela primeira vez no começo da década de 1920, pelo psicólogo Edward Thorndike. Sua definição era "a habilidade de entender e administrar homens e mulheres, meninos e meninas - para agir sabiamente nas relações humanas" (Thorndike apud Kihlstrom \& Cantor, 2004, p. 359, tradução nossa) e era parte integrante das três facetas que compunham o conceito de inteligência proposta por ele: inteligência abstrata (a habilidade de entender e administrar ideias), inteligência mecânica (em relação aos objetos concretos) e inteligência social (voltada para as pessoas).

O conceito recebeu aceitação entre os psicólogos da década seguinte: Moss e Hunt, em 1927, definiram a inteligência social como a habilidade de se relacionar bem com os outros

Revista de Gestão e Secretariado - GeSec, São Paulo, v. 5, n. 2, p 23-48, mai./ago. 2014. 
(Kihlstrom \& Cantor, 2004).

Em 1933, Vernon propôs uma definição mais ampla, que era a

habilidade de se relacionar bem com as pessoas em geral, técnica social ou facilidade na sociedade, conhecimento de modos sociais, sensibilidade aos estímulos de outros membros do grupo, bem como compreensão das variações de humor ou reconhecimento dos traços de personalidade de pessoas estranhas. (Vernon apud Kihlstrom \& Cantor, 2004, p. 359, tradução nossa).

Entretanto, em 1939, David Weschler atribuiu pouca atenção ao termo, definindo a inteligência social somente como uma inteligência geral aplicada às situações sociais. A partir de então houve uma gradativa perda de interesse pelo conceito, pois naquela época os testes de QI possuíam enorme aceitação entre os pesquisadores, pela sua facilidade de aplicação e de demonstração de resultados. Adicionalmente, os testes para a mensuração da inteligência social demonstraram-se de difícil criação, com poucas experiências satisfatórias, sendo um dos maiores problemas a dificuldade de construção de instrumentos de inteligência social válidos e, consequentemente, de aplicação, pois iriam exigir testes em laboratórios com seres humanos e tendo como objeto de análise semblantes, voz, gestos e atitudes (Kihlstrom \& Cantor, 2004; Walker \& Foley, 1973).

No início dos anos de 1980, Howard Gardner, professor de psicologia de Harvard, começou a questionar certos tópicos contrastantes relativos aos testes psicológicos, como por exemplo: por que muitas pessoas com alto nível de QI se demonstram inversamente inteligentes em relação a suas vidas pessoais? Por que certas habilidades humanas, como a competência artística, musical, atlética, literária e social são negligenciadas nos testes de inteligência? Seria a inteligência humana uma entidade mensurável e tangível? Partindo de tais questionamentos, Gardner afirma que os seres humanos possuem uma gama de inteligências, não sendo válido considerar a inteligência como sendo de um único traço, medida apenas pelos testes de QI. Ele desenvolve, então, o modelo de múltiplas inteligências, considerado um divisor de águas na compreensão e definição das fontes da competência mental. Dentro da esfera das inteligências múltiplas, encontra-se a competência em situações humanas (Gardner, 1994; Albrecht, 2006).

Em virtude dos novos paradigmas acerca da inteligência humana, aliado aos avanços no campo da neurociência e o surgimento da neurociência social, a inteligência social volta a despertar interesse como linha de pesquisa.

Karl Albrecht (2006) situa a inteligência social dentro da perspectiva das inteligências múltiplas, fazendo uma releitura dos conceitos apresentados por Gardner: o que foi abordado

Revista de Gestão e Secretariado - GeSec, São Paulo, v. 5, n. 2, p 23-48, mai./ago. 2014. 
como "inteligência interpessoal", na visão de Albrecht passa a ser denominado de "inteligência social". Para o autor, esse tipo de inteligência consiste tanto de percepção como de comportamento, sendo conceituada como a habilidade de se relacionar bem com as outras pessoas e de conseguir a cooperação delas.

Tony Buzan (2005, p. 14) denomina a inteligência social como "a capacidade de nos darmos bem e de nos relacionarmos com as pessoas ao nosso redor." Segundo Buzan, as pessoas socialmente inteligentes são as que se destacam nos primeiros encontros, sendo lembradas por sua simpatia e cordialidade, pela atitude positiva e o interesse pelas demais pessoas. Ressalta, ainda, que esta é uma das inteligências mais importantes e benéficas para o ser humano, acrescentando o fato de que ela pode ser desenvolvida: estar atento à linguagem corporal e ter consciência da "zona de conforto" de cada um, além de ouvir realmente as pessoas, focando a atenção nelas são algumas das maneiras de ativar a inteligência social.

Daniel Goleman (2006), autor do best-seller Inteligência Emocional, aprofunda-se na nova ciência, propondo pensá-la "como um termo que resume ser inteligente não apenas a respeito dos nossos relacionamentos, mas também em nossos relacionamentos" (p. 13, grifo no original), afirmando que o conceito amplia o foco da visão de uma pessoa como o proposto na inteligência emocional, para a perspectiva de duas pessoas, das habilidades que se desenvolvem quando a pessoa se envolve em um relacionamento.

De modo a estimular essa nova linha de pensamento, Goleman (2006) propõe um modelo de inteligência social, a partir do qual, o conceito poderá ser expandido.

A seguir, apresenta-se o modelo criado pelo autor:

Revista de Gestão e Secretariado - GeSec, São Paulo, v. 5, n. 2, p 23-48, mai./ago. 2014. 
Figura 1 - O modelo de inteligência social de Daniel Goleman.

\section{N T E L I G Ê N C I A S O C C I A L \\ Consciência social}

A consciência social refere-se a um espectro que vai de sentir instantaneamente o estado interno do outro e compreender seus sentimentos e pensamentos a "entender" situaçōes sociais complicadas. Inclui:

- Empatia primordial: Sentir com os outros; sentir os sinais emocionais nāo-verbais.

- Sintonia: Ouvir com total receptividade; sintonizar-se com o outro.

- Precisão empática: Entender os pensamentos, sentimentos e intençōes do outro.

- Cogniçāo social: Saber como funciona o mundo social.

\section{Facilidade social}

Nāo basta sentir como os outros se sentem, ou saber o que pensam ou pretendem, para garantir interaçōes produtivas. A facilidade social se baseia na consciência social para permitir interaçōes fluentes e eficazes. $O$ espectro da facilidade social inclui:

- Sincronia: Interaçāo fluente no nível nāo-verbal.

- Apresentação pessoal: Apresentar-se de maneira eficiente.

- Influência: Moldar o resultado das interaçoes sociais.

- Preocupação: Importar-se com as necessidades dos outros e agir com base nelas.

Fonte: Goleman (2006).

Conforme demonstrado na Figura 1, a inteligência social pode ser organizada em duas categorias: a consciência social - os sentimentos em relação aos outros - e a facilidade social o que se faz da posse dessa consciência. Afinal, para uma pessoa ser inteligente socialmente, não basta somente estar consciente, é preciso também agir. A sabedoria social será reconhecida por meio das ações, da influência positiva que elas exercem nas interações sociais.

\subsection{A INTELIGÊNCIA SOCIAL PARA O PROFISSIONAL DE SECRETARIADO EXECUTIVO}

Reconhecida como uma das profissões mais antigas do mundo, tendo como exemplo os escribas do antigo Egito, e presente em momentos relevantes da história, como na inserção da mulher no mercado de trabalho, a profissão só foi regulamentada no Brasil em 1985 (lei nº 7.377 ,

Revista de Gestão e Secretariado - GeSec, São Paulo, v. 5, n. 2, p 23-48, mai./ago. 2014. 
de 30/09/1985 e complementada pela lei no 9.261, de 10/01/1996), devido aos esforços associativos de profissionais que perceberam a necessidade de desvincular-se da categoria dos administradores para buscar uma identificação própria (Bianchi, Alvarenga \& Bianchi, 2003; Martins et al., 2012).

O perfil do profissional de Secretariado Executivo acompanha as mudanças e tendências dos ambientes corporativos: se há poucas décadas a formação na área era raramente exigida, atualmente é requerida escolaridade de nível superior, assim como cursos de pós-graduação, cursos de aprimoramento e o domínio de outros idiomas. Se antigamente as atividades exercidas eram somente operacionais, hoje, o profissional também é gestor e empreendedor. Se a relação com o superior se baseava somente na execução das tarefas designadas, hoje, é uma relação de parceria (Neiva \& D'Elia, 2009).

De acordo com o art. $8^{\circ}$ das Diretrizes Curriculares Nacionais do curso de Secretariado Executivo, o profissional deve ser preparado para realizar

o eficaz desempenho de múltiplas relações de acordo com as especificidades de cada organização, mantendo o harmônico funcionamento nas interfaces staffllinha, gerenciando o fluxo de informações e desenvolvendo com sensibilidade metodologias capazes de diagnosticar e gerenciar conflitos e mudanças. (Brasil, 2002).

Deve, ainda, apresentar um perfil

profissional proficiente, criativo, participativo, conhecedor de gestão estratégica, articulador em negociações que precedam à tomada de decisões, facilitador das relações interpessoais e intergrupais, revelando eficiente domínio de técnicas de sensibilização, e de fácil domínio dos diferentes meios de comunicação dentro da organização e com diferentes grupos de clientela e de demanda. (Brasil, 2002).

Na visão de Neiva e D’Elia (2009, p. 29, grifo no original), “falar do perfil do profissional secretário é tirar a fotografia do dia a dia empresarial." Nesse sentido, as autoras falam da polivalência da profissão, ou seja, do leque de possibilidades de atuações do profissional, enumerando algumas de suas características atuais: a) a de ser um agente de resultados: como profissional que trabalha ao lado do poder decisório, o secretário mais do que nunca precisa ser um gerador de resultados. Para isso, é preciso ter uma visão global: do conhecimento de negócio, da cultura e filosofia da empresa, da visão, da missão e dos objetivos e metas. Alguns desses indicadores são formais e escritos, outros são informais e invisíveis, sendo observados no comportamento das pessoas; b) agente facilitador: a comunicação é uma das competências mais

Revista de Gestão e Secretariado - GeSec, São Paulo, v. 5, n. 2, p 23-48, mai./ago. 2014. 
importantes para o profissional secretário atuar como agente facilitador. Ela pode ser verbal ou não verbal, através dos gestos, expressões faciais e posturas; c) agente de qualidade: a qualidade é uma questão de sobrevivência para a permanência de empresas e profissionais no mercado, sendo importante o envolvimento do profissional secretário nos programas de qualidade, bem como na busca pela excelência no atendimento ao cliente (interno ou externo), e; c) agente de mudanças: pelo fato de atuar ao lado das pessoas que promovem as mudanças nas organizações, é exigida do secretário uma postura de parceria, o que envolve ser o primeiro profissional a atendê-las, aceitálas, praticá-las e, principalmente, que seja um agente multiplicador.

Segundo Wamser (2010), as competências essenciais para a formação do secretário executivo são: a) competência técnica: possuir o domínio e a aplicação de métodos secretariais e gerenciais em áreas específicas de atuação, fazendo uso de ferramentas, materiais, procedimentos, normas e sistemas corporativos; b) competência comunicacional: conhecimento dos princípios técnicos da comunicação oral e escrita, tendo como objetivo aprimorar a comunicação com clientes internos e externos, garantir a qualidade da informação e promover a imagem corporativa, e c) competência social: fundamental para conviver harmoniosamente com as pessoas no ambiente profissional e social.

Dentre as diversas facetas inerentes ao secretário executivo, é o desempenho na rede de relações interpessoais que administra onde ele deixará a sua marca, pois a sua percepção do ambiente, das pessoas, dos códigos ditos e dos implícitos, o equilíbrio emocional, a visão global da empresa, a criatividade na relação personalizada com o cliente são aspectos que facilitarão o convívio com o executivo, colegas, clientes e fornecedores (Neiva \& D’Elia, 2009).

Considerando essa dinâmica da atuação do Secretário Executivo, um maior conhecimento em relação a habilidades que potencializem o bom desempenho nos relacionamentos, é de extrema relevância para o desenvolvimento profissional. Nesse sentido, a inteligência social contribui para o aprimoramento dessas habilidades, uma vez que seus estudos são baseados nas interações sociais e, em como essas interações influenciam, positivamente ou negativamente, as pessoas envolvidas. Estudar e praticar essa competência, de modo a tornar-se socialmente inteligente contribuirá para uma atuação mais proativa e colaborativa no ambiente em que o profissional está inserido.

Revista de Gestão e Secretariado - GeSec, São Paulo, v. 5, n. 2, p 23-48, mai./ago. 2014. 


\section{METODOLOGIA}

O método escolhido para este trabalho é caracterizado como exploratório, com uma abordagem qualitativa de pesquisa, adotando-se os procedimentos técnicos de tipo bibliográfico e de estudo de campo. É exploratório por ser considerado um assunto com pouca pesquisa realizada, e por ter o objetivo de familiarizar-se com o fenômeno ou obter nova percepção dele e de descobrir novas ideias e as relações existentes entre os elementos componentes (Cervo \& Bervian, 1983). Para a coleta de dados, são utilizadas as técnicas de pesquisa bibliográfica, especialmente no levantamento do aparato teórico, em que são abordados os estudos de autores que tratam da inteligência social, bem como das informações relacionadas a esse tema presentes na literatura do secretariado, e de pesquisa de campo, por meio de um questionário de questões abertas, desenvolvidas pelas autoras (ver Apêndice), e que foi aplicado a uma secretária executiva com o objetivo de identificar na realidade do profissional a relevância deste tema para a área secretarial.

A profissional escolhida para participar da pesquisa exerceu a função de secretária durante nove anos em empresas privadas, e durante vinte e dois anos em uma empresa pública na cidade de Florianópolis (SC). A seleção da participante ocorreu por amostra intencional, devido à sua considerável experiência profissional na área; aos diferentes ambientes em que atuou (público e privado); e pela disponibilidade em participar da pesquisa.

Os dados coletados foram analisados a partir dos discursos referentes aos aspectos do modelo de inteligência social de Daniel Goleman: empatia primordial; sintonia; precisão empática; cognição social; sincronia; apresentação pessoal; influência; e preocupação.

\section{DISCUSSÃO DOS RESULTADOS}

Esta seção será dividida em duas seções secundárias: a primeira apresenta uma discussão do modelo de inteligência social proposto por Goleman (2006), relacionando-o com Secretariado Executivo e os dados obtidos por meio do questionário. A segunda, por sua vez, apresenta a discussão da possibilidade de um modelo de inteligência social para o Secretariado Executivo.

Revista de Gestão e Secretariado - GeSec, São Paulo, v. 5, n. 2, p 23-48, mai./ago. 2014. 


\subsection{ANÁLISE DO MODELO DE INTELIGÊNCIA SOCIAL DE DANIEL GOLEMAN E SUA RELAÇÃO COM O SECRETARIADO EXECUTIVO}

Num primeiro momento será analisado cada aspecto, das duas categorias, do modelo de inteligência social de Goleman, para então relacioná-los com os discursos presentes na literatura do secretariado. Por fim, serão utilizados trechos das respostas de uma secretária executiva acerca da relevância desses aspectos em sua experiência profissional.

\section{Consciência social}

$\checkmark \quad$ Empatia primordial: Sentir com os outros; sentir os sinais emocionais não verbais. Esse tipo de empatia ocorre - ou não - de maneira rápida e automática. É ativada, em grande parte, pelos neurônios-espelho. Alguns testes, como o "Reading the Mind in the Eyes" (Leitura da mente pelos olhos), criado por Simon Baron-Cohen, da Universidade de Cambridge, em que é preciso adivinhar o que os olhos estão comunicando, indicam se a pessoa é dotada de empatia ou não (casos extremos revelam autismo) (Goleman, 2006).

Segundo Medeiros e Hernandes (2010), da secretária moderna exigem-se não só conhecimentos técnicos, como também de comportamento interpessoal e compreensão das pessoas com quem se relaciona e, para compreender bem as pessoas, é necessário colocar-se dentro do mundo psicológico delas e observar o seu comportamento, ou seja, sentir o que os outros pensam e sentem.

De acordo com o relato da entrevistada,

A empatia [...] é primordial no exercício da profissão de secretariado. É desta forma que podemos antecipar-nos no atendimento eficaz das pessoas com as quais é necessário manter um relacionamento constante. Começando pelo gestor(a) que assessoramos e estendendo este conhecimento para as pessoas com as quais convivemos no trabalho: colegas, clientes, fornecedores e visitantes. Na medida que [sic] progredimos nesta capacidade de sentir as emoções do "outro" aumenta a facilidade de darmos a resposta adequada ao desejo da pessoa que $[\mathrm{sic}]$ estamos nos relacionando. (grifo no original).

$\checkmark \quad$ Sintonia: Ouvir com total receptividade; sintonizar-se com o outro. É oferecer total atenção a uma pessoa, ouvindo-a até o fim, procurando entendê-la, ao invés de simplesmente expor uma opinião. Esta dimensão da inteligência social, assim como as demais, pode ser melhorada: basta prestar mais atenção intencionalmente. É preciso deixar de lado o que se está fazendo, largar o memorando que se está lendo, desviar os olhos do computador e prestar atenção no que a outra

Revista de Gestão e Secretariado - GeSec, São Paulo, v. 5, n. 2, p 23-48, mai./ago. 2014. 
pessoa está transmitindo. Ouvir com cuidado, com atenção total, orienta os circuitos neurais para a conectividade (Goleman, 2006).

Na visão de Medeiros e Hernandes (2010, p. 62):

A secretária deve habituar-se a encorajar as pessoas a manifestarem seus verdadeiros sentimentos, desejos e emoções. Deve aprender a ouvir. Por isso, há de parar de falar quando alguém está falando; colocar-se à vontade e proporcionar clima agradável e motivador para o outro expor suas ideias; mostrar interesse em ouvir; fugir das distrações; a atitude deve ser de empatia [...] Antes, porém, de se seguir cegamente qualquer lista de normas, deve tomar a decisão de ouvir, ouvir, ouvir.

"O profissional de secretariado deve buscar sua fórmula para "ouvir" o outro, mesmo que sua atenção esteja voltada para todas as atividades técnicas - urgentes e prioritárias - que necessita fazer ou resolver", pois "isso facilita o relacionamento, acalma a ira - por exemplo, de um cliente irritado, de um colaborador desmotivado". A entrevistada ressalta, ainda, o fato de que "uma pessoa 'sintonizada' para ouvir com atenção torna-se antenada a quaisquer situações que encontra. Isso torna o profissional pró-ativo [sic], ao invés de reativo".

$\checkmark \quad$ Precisão Empática: Entender os pensamentos, sentimentos e intenções do outro. Baseia-se na empatia primordial, mas acrescenta um entendimento explícito do que o outro sente e pensa. Como revelou a descoberta dos neurônios-espelho, o cérebro é capaz de entrar em sintonia com o que alguém pretende fazer, mas faz isso de modo subliminar. A percepção consciente das intenções de alguém propicia uma empatia mais precisa; desse modo é mais fácil prever o que aquela pessoa fará. É considerada a especialidade essencial da inteligência social, sendo a capacidade que distingue os negociadores mais eficientes, os vendedores mais produtivos e os políticos mais queridos, por exemplo (Goleman, 2006).

Conforme afirmam Neiva e D’Elia (2009, p. 31, grifo no original), “entender de gente é algo inerente a quem é agente facilitador" e, complementam que quanto mais entendimento acerca das particularidades de uma pessoa, mais fácil será o aperfeiçoamento da comunicação, pois, para o profissional de secretariado que trabalha com pessoas e assessora níveis decisórios, esse conhecimento pode ajudar a personalizar sua comunicação.

Segundo o depoimento concedido: "É comum dizer que o profissional de secretariado tem um "sexto sentido". Este sexto sentido, a capacidade de antever as situações e emoções futuras faz com que o secretário possa prever uma reação positiva com muito maior [sic] precisão". (grifo no

Revista de Gestão e Secretariado - GeSec, São Paulo, v. 5, n. 2, p 23-48, mai./ago. 2014. 
original).

$\checkmark \quad$ Cognição social: Saber como funciona o mundo social. As pessoas competentes nessa variedade de cognição sabem o que esperar na maior parte de qualquer situação social, como ter uma postura profissional condizente ao ambiente de trabalho, e sabem decodificar os sinais que revelam, por exemplo, quem deve ser a pessoa mais poderosa em um grupo. Esse entendimento social pode ser visto naqueles que leem com exatidão as correntes políticas de uma organização, que são capazes de entender as normas implícitas que governam as interações. Uma maneira como a cognição social pode manifestar-se é a capacidade de encontrar soluções para dilemas sociais, como a disposição dos lugares de inimigos em um jantar comemorativo (Goleman, 2006).

Segundo Medeiros e Hernandes (2010), cabe à secretária

conhecer as pessoas envolvidas no processo de produção, os gerentes, ter noção da divisão do trabalho estabelecido na empresa, reconhecer a autoridade competente [..] É necessário conhecimento profundo do que a empresa produz ou dos serviços que presta, dos funcionários que nela trabalham, do comportamento do executivo que a secretária assessora. (p. 284).

É recomendável que a secretária procure observar o comportamento prevalecente no escritório, os valores tidos em maior conta, os objetivos profissionais das pessoas que estão a sua volta, particularmente de seu executivo, capacidade comunicativa e os métodos de trabalho dele. (p. 320).

De acordo com Wamser (2010 p. 67), para o profissional de secretariado, saber "prestar atenção aos hábitos, atitudes, boas maneiras e normas de conduta - nem sempre escritas, mas que regem o comportamento social e profissional - pode ser um fator preponderante para a conquista de uma carreira bem-sucedida." Ainda, segundo a autora, quanto maior o conhecimento da empresa em que trabalha, seu negócio, suas normas e procedimentos, mais dinamismo agregará ao trabalho e maior será a probabilidade de criar situações e oportunidades para argumentar, opinar, participar e sugerir mudanças.

Segundo Neiva e D’Elia (2009, p. 42, grifo no original) “é importante que o secretário fique atento a todos os detalhes. É necessário "ler" todos os dados explícitos e não explícitos. É vital buscar essas informações, que serão ferramentas indispensáveis à sua atuação."

De acordo com a secretária entrevistada, "transitar nos diferentes ambientes e comportar-se adequadamente em cada um deles é uma excelente habilidade no exercício profissional", e cabe ao secretário "conhecer igual ou melhor que seu gestor, para que possa representá-lo ou mesmo

Revista de Gestão e Secretariado - GeSec, São Paulo, v. 5, n. 2, p 23-48, mai./ago. 2014. 
auxiliá-lo quando o ambiente não for do seu conhecimento", afinal "gestores e colaboradores transitam em ambientes organizacionais, sociais e que envolvem interações de toda ordem”. Vale ressaltar que "a maturidade profissional e pessoal é fator primordial para que o secretariado [sic] tenha a habilidade natural necessária para exercer com propriedade essa tarefa".

\section{Facilidade social}

$\checkmark \quad$ Sincronia: Interação fluente no nível não verbal. É o pilar sobre o qual se assentam os outros aspectos da facilidade social. Acontece quando as pessoas conseguem ler instantaneamente as dicas não verbais e agir em sintonia - sem ter de pensar a respeito. As pessoas que se saem mal nessa habilidade social costumam sofrer de "dissemia", a incapacidade de ler e agir de acordo com os sinais não verbais que orientam as interações fluentes. Pessoas dissêmicas não são atentas, por exemplo, aos indícios de que uma conversa está chegando ao fim (Goleman, 2006).

No âmbito do secretariado, de acordo com Neiva e D’Elia (2009, p. 58, grifo no original),

O executivo, mais do ninguém, necessita da sua sintonia, do seu rápido entendimento dos códigos ditos e não ditos. Ele espera que você capte "no ar" como está o clima organizacional, o que é urgente e o que pode esperar, como está o humor dele etc.

Nesse sentido, a secretária entrevistada afirma que "é primordial que secretariado [sic] tenha essa habilidade muito desenvolvida para poder construir relacionamentos de sucesso profissional" e, pode desenvolvê-la ao prestar mais atenção "aos ambientes, às atitudes, à maneira de vestir e falar das pessoas", pois "as pessoas falam mais com o corpo, gestos e olhares do que com palavras".

$\checkmark \quad$ Apresentação pessoal: Apresentar-se de maneira eficiente, que cause a impressão adequada. Muitas vezes, a capacidade de "controlar" e "mascarar" a expressão das emoções é considerada o segredo da apresentação pessoal. Na maioria dos locais de trabalho é preciso conter os impulsos para se encaixar. Entretanto, essa capacidade não pode ocorrer isolada, é necessário algo que a sustente, no caso profissional, a habilidade técnica (Goleman, 2006).

Segundo Medeiros e Hernandes (2010, p. 320), "Em geral, os executivos preferem uma profissional que possa ser sua assistente a uma profissional que apenas tira partido de sua apresentação impecável”. Contudo, vale estar atenta à apresentação pessoal esperada do profissional

Revista de Gestão e Secretariado - GeSec, São Paulo, v. 5, n. 2, p 23-48, mai./ago. 2014. 
de secretariado, afinal, "como a secretária representa a empresa, sua postura física deve ser equilibrada [...]. A secretária também se comunica com outros meios que não a palavra: gestos, expressões corporais, vestuário.” (2010, p. 332).

A capacidade de "controlar" e "mascarar" as emoções é relacionada à discrição e sigilo que a profissão exige:

\begin{abstract}
A profissão de secretária exige discrição. Muitas informações que lhe são confiadas ela não as pode divulgar. [...] se quiser manter alto grau de profissionalismo e estima de todos, deverá manter-se calada sobre tais notícias, principalmente sobre aquelas conhecidas pelo nome de fofoca. (Medeiros \& Hernandes, 2010, p. 319, grifo no original).
\end{abstract}

Para Neiva e D’Elia (2009), a imagem profissional do secretário deve ser baseada nas habilidades técnicas e nos aspectos da postura e comportamento social, neste sentido, ressalta-se a importância da ética, da etiqueta e da vestimenta adequada.

Conforme a opinião da entrevistada,

\begin{abstract}
A apresentação pessoal do secretário é a imagem da organização, pois está de destaque, começando pelo espaço físico que ocupa. A imagem profissional não está baseada apenas na maneira de vestir-se. Integram uma imagem positiva um vocabulário inteligente, a maneira de receber com cortesia, maneira de andar, gesticular, atender, ouvir com atenção. É um conjunto de palavras, gestos e atitudes que formam a imagem profissional. E a partir desse conjunto o secretário pode construir ou destruir relacionamentos e a própria imagem organizacional.
\end{abstract}

$\checkmark \quad$ Influência: Moldar o resultado das interações sociais. É uma combinação de autocontrole, empatia e cognição social. Para obter influência construtiva, é preciso expressar-se de maneira que produza um resultado social adequado, tendo consciência do que é adequado em um contexto social específico, ou seja, o tato equilibra a expressividade. Os adeptos do emprego da influência utilizam a percepção social para orientar suas ações. A discrição social permite encaixar-se em qualquer lugar, deixando menos ondulações emocionais inconvenientes (Goleman, 2006).

Em algumas organizações, o secretário exerce funções em que tem a obrigação de controlar tarefas atribuídas a funcionários que estão sob sua responsabilidade. Também, na sua atuação como "ponte" e agente facilitador dos relacionamentos e processos de trabalho, ele atua como porta-voz do gestor que assessora, outras como coordenador de informações, prazos e providências junto à equipe de gestores, outras equipes, pares, clientes internos. É na vasta rede de relacionamentos, com perfis heterogêneos, diferentes graus de poder e hierarquia, que a liderança do secretário atua e exerce a sua importância (Medeiros \& Hernandes, 2010; Neiva \& D’Elia, 2009).

Revista de Gestão e Secretariado - GeSec, São Paulo, v. 5, n. 2, p 23-48, mai./ago. 2014. 
A eficácia de uma comunicação de ordens e a capacidade persuasiva da secretária dependem de seu conhecimento preciso daquilo que quer comunicar [...] É necessário considerar a capacidade do receptor, sua disponibilidade de tempo e capacidade de ação [...] deverá ter presente que é necessário merecer o respeito do receptor e inspirar confiança. (Medeiros \& Hernandes, 2010, p. $14)$.

De acordo com a resposta da secretária entrevistada, "a influência [...] está intimamente relacionada na forma como o secretariado [sic] apresenta-se ou comporta-se no seu ambiente profissional", seja por meio do seu "comportamento, atitudes, ações e palavras adequadas a cada situação", o que resulta em "um comportamento ideal para que o secretariado [sic] mantenha uma influência positiva no ambiente de trabalho, para clientes internos e externos".

$\checkmark \quad$ Preocupação: Importar-se com as necessidades dos outros e agir com base nelas, afinal, a empatia, isoladamente, importa pouco se não houver alguma ação. Reflete a capacidade de compaixão. As pessoas fisiologicamente mais estimuladas pelo sofrimento alheio, ou seja, altamente suscetíveis ao contágio emocional nesse sentido, são as que mais se mobilizam para ajudar. No ambiente de trabalho, a preocupação que impulsiona a assumir responsabilidades pelo que precisa ser feito se traduz em boa cidadania organizacional. As pessoas preocupadas são as mais dispostas a ajudar um colega de trabalho. Em vez de se concentrar apenas nas suas tarefas, elas entendem a necessidade de cooperação em grupo para alcançar os objetivos maiores (Goleman, 2006).

Uma das principais qualidades desejáveis da secretária é a sua capacidade de promover boas relações no escritório, com executivos, auxiliares, colegas e visitantes. O fluxo uniforme e harmonioso do trabalho depende da forma como a secretária trabalha com os outros e de como os influencia (Medeiros \& Hernandes, 2010).

Executivos e secretários geram mais resultados e aumentam sua produtividade quanto atuam em equipe. Certamente, o ideal é que haja uma adaptação recíproca, porém, cabe ao secretário o ajustamento ao perfil do(s) executivo(s), por ser ele um prestador de serviços (Neiva \& D'Elia; 2009).

Na visão da entrevistada, a preocupação é um dos aspectos que auxilia na construção da imagem profissional do secretário:

Revista de Gestão e Secretariado - GeSec, São Paulo, v. 5, n. 2, p 23-48, mai./ago. 2014. 
O secretário é um colaborador da empresa. Presta assessoria imediata a seu superior, mas a preocupação com o bem-estar da organização e das pessoas que ali prestam seus serviços deve ser constante. Não há outra maneira do secretário construir sua imagem pessoal e profissional positiva. Igualmente não poderia representar adequadamente seu superior ou a própria organização.

A partir da discussão exposta foi possível identificar a relevância desse tema para a área secretarial e através de tal constatação é plausível a incorporação da inteligência social ao perfil profissional do secretário executivo.

\subsection{DISCUSSÃO ACERCA DA POSSIBILIDADE DE ELABORAÇÃO DE UM MODELO DE INTELIGÊNCIA SOCIAL PARA O SECRETARIADO EXECUTIVO}

A fim de exemplificar a relação entre o tema e a área abordados, apresentam-se ideias para uma modelo, as quais têm o intuito promover a discussão sobre a possibilidade de elaboração de um modelo de inteligência social para a área secretarial, conforme consta no Quadro 1:

\section{INTELIGÊNCIA SOCIAL PARA O SECRETARIADO EXECUTIVO}

\section{Consciência Social}

$\checkmark$ Empatia primordial: é a capacidade de perceber os sentimentos e intenções não verbalizados de outra pessoa, seja um cliente, colega ou gestor, o que proporciona melhor compreensão entre eles e uma interação com resultados mais satisfatórios.

$\checkmark \quad$ Sintonia: é ouvir dedicando total atenção ao emissor da mensagem. Para que isso seja possível, a(o) secretária(o) deve evitar interferências, tais como interromper a outra pessoa ou continuar suas atividades sem prestar atenção a ela, mais do que isso, o profissional deve preocupar-se em proporcionar um ambiente onde a expressão de opiniões é valorizada.

$\checkmark \quad$ Precisão empática: mais do que perceber, é entender o que o outro sente e pensa. Esse entendimento sobre as outras pessoas é o respeito que o profissional precisa ter em relação aos demais colaboradores e o que faz diferenciá-lo no ambiente organizacional, pois estará mais apto para corresponder de modo condizente e poderá, até mesmo, antecipar-se nas ações a serem tomadas.

$\checkmark$ Cognição social: saber quais são as regras e valores explícitos e implícitos que regem os ambientes em que o profissional de secretariado atua, e agir de maneira eficiente em relação a eles, de modo a encontrar soluções para conflitos. Pode ser considerado como um dos fatores para o alcance de uma carreira bem sucedida.

Revista de Gestão e Secretariado - GeSec, São Paulo, v. 5, n. 2, p 23-48, mai./ago. 2014. 


\section{Facilidade Social}

$\checkmark \quad$ Sincronia: é a capacidade de ler os sinais não verbais e agir em sintonia. Essa habilidade é possível através da atenção dispensada a esse tipo de sinais (atitudes, vestuário, gestos, tom de voz etc.), sendo um dos fatores que viabilizam melhores relações profissionais, especialmente na relação gestor-assessor.

$\checkmark$ Apresentação pessoal: apresentar-se de modo que cause a impressão adequada, tanto na maneira de vestir-se, portar-se e dirigir-se às pessoas. É o conjunto de atitudes (tais como discrição, sigilo, cortesia) que constroem a imagem profissional da(o) secretária(o) de maneira positiva.

Influência: é a capacidade de conseguir os resultados esperados através de sua capacidade de expressão (verbal e comportamental), que deve estar em concordância com o contexto/pessoas em questão. O profissional de secretariado que se comunica eficazmente e porta-se adequadamente exerce com mais facilidade sua influência no ambiente corporativo.

$\checkmark \quad$ Preocupação: reflete o espírito de equipe e a responsabilidade e comprometimento que o profissional de secretariado deve manter em relação à suas atribuições no trabalho. Este é um aspecto de extrema importância para a(o) secretária(o), pelo fato de relacionar-se com colegas de diferentes áreas da empresa e níveis hierárquicos, e colaboradores externos, além de ser considerado um cargo de confiança do poder decisório nas organizações.

Quadro 1 - Inteligência Social para o Secretariado Executivo Fonte: Elaborado pelas autoras.

Para a elaboração das ideias do Quadro 1, buscou-se manter a estrutura do modelo de Goleman: com as duas categorias e seus respectivos aspectos, bem como suas denominações originais. A explicação de cada aspecto manteve a ideia de Goleman, porém contextualizada com a realidade do profissional de secretariado, sendo que esse conhecimento proveio das informações coletadas nos livros da área e do relato da experiência profissional de uma secretária executiva. Pelo fato de ser possível relacionar os pressupostos do modelo de Goleman com as competências comportamentais e de relacionamento esperadas do profissional de secretariado executivo, é que se julgou pertinente a discussão da possibilidade de criação de um modelo para o secretariado.

Destaca-se que as ideias propostas representam uma discussão inicial para a elaboração do modelo e, uma sugestão de como elas poderiam ser expandidas. O objetivo principal é estimular esta linha de pensamento, pois estudos mais profundos e mais pesquisas realizados com uma maior variedade de profissionais em diferentes ambientes organizacionais e considerando-se a percepção dos gestores, fazem-se necessários para construir uma base de dados capaz de consolidar a ideia

Revista de Gestão e Secretariado - GeSec, São Paulo, v. 5, n. 2, p 23-48, mai./ago. 2014. 
de um modelo direcionado à área secretarial.

\section{CONSIDERAÇÕES FINAIS}

Os estudos da neurociência social demonstram as implicações que os relacionamentos possuem sobre a biologia humana, quantificando seus benefícios e seus malefícios. Deste modo, é igualmente importante estar consciente a respeito das consequências que as interações sociais refletem sobre nós, bem como do impacto que exercemos sobre os outros - desde os que encontramos casualmente até aqueles que mais amamos. Nesse sentido, a responsabilidade social torna-se importante, no sentido de agir de maneira a proporcionar estados benéficos nos outros.

Sob essa perspectiva, por ser um agente facilitador no ambiente organizacional e por possuir uma posição que exige certa dose de habilidade no relacionamento com colegas, clientes e superiores, o profissional de secretariado executivo necessita de conhecimentos e esclarecimentos que lhe permitam aprimorar seu desempenho na rede de relacionamentos que administra.

A inteligência social é um conceito que procura aprofundar-se nas habilidades pertinentes ao cultivo dos bons relacionamentos humanos e o modelo proposto por Goleman demonstra-se contextualizado à realidade e às demandas do profissional de secretariado, pois de acordo com a discussão exposta, os aspectos da inteligência social são aplicáveis à área secretarial.

Vale destacar a relevância de alguns aspectos: a) precisão empática, pelo fato da habilidade de entender de pessoas ser algo característico deste profissional; b) cognição social, que pode ser vista como uma habilidade necessária para o dia a dia secretarial e para a consolidação de uma carreira de sucesso; c) sincronia, valiosíssima para o relacionamento com o(s) executivo(s) que ele assessora; d) apresentação pessoal, por ser considerado, muitas vezes, a imagem da empresa é importante o secretário estar atento à mensagem que repassa aos demais; e) preocupação, ser prestativo com os colegas de trabalho e a quem assessora é uma das qualidades desejáveis a este profissional.

Por se tratar de uma pesquisa exploratória, que teve como objetivo familiarizar-se com o assunto e estabelecer uma relação entre os objetos de estudo, este trabalho apresentou subsídios para a discussão inicial da possibilidade de se propor um modelo de inteligência social direcionado ao Secretariado Executivo.

Compreendendo a importância da geração de conhecimentos mais aprofundados sobre esse tema na área secretarial, sugere-se a ampliação da discussão apresentada neste trabalho,

Revista de Gestão e Secretariado - GeSec, São Paulo, v. 5, n. 2, p 23-48, mai./ago. 2014. 
realizando-se mais pesquisa de campo com maior quantidade de profissionais da área, que atuem em diferentes organizações - públicas e privadas - e, também, levando em consideração as percepções dos gestores. Deste modo, será possível buscar o delineamento de um modelo de inteligência social para o Secretariado Executivo.

\section{REFERÊNCIAS}

Albrecht, K. (2006). Inteligência Social: a nova ciência do sucesso. São Paulo: M. Books do Brasil.

Bianchi, A. C. M.; Alvarenga, M. \& Bianchi, R. (2003). Orientação para estágio em secretariado: trabalhos, projetos e monografias. São Paulo: Pioneira Thomson Learning.

Brasil (2002). Ministério da Educação. Diretrizes Curriculares dos Cursos de Graduação. Parecer CNE/CES n 146, de 3 de abril de 2002. Apresenta as Diretrizes Curriculares Nacionais do curso de Secretariado Executivo. Recuperado em 27 de janeiro 2013, de <http://portal.mec.gov.br/index.php?option=com_content\&view=article\&id=12991>.

Buzan, T. (2005). O poder da inteligência social: 10 maneiras de ativar o seu gênio social. São Paulo: Cultrix.

Cacioppo, J. T. \& Decety, J. (2011). Social neuroscience: challenges and opportunities in the study of complex behavior. Recuperado em 20 de janeiro, 2013, de <http://psychology.uchicago.edu/people/faculty/cacioppo/cd2011.pdf>.

Cervo, A. L. \& Bervian, P. A. (1983). Metodologia científica: para uso dos estudantes universitários (3a ed.). São Paulo: MacGraw-Hill do Brasil.

Gardner, H. (1994). Estruturas da mente: a teoria das inteligências múltiplas. Porto Alegre: Artes Médicas Sul.

Goleman, D. (2006). Inteligência Social: o poder das relações humanas. Rio de Janeiro: Elsevier.

Revista de Gestão e Secretariado - GeSec, São Paulo, v. 5, n. 2, p 23-48, mai./ago. 2014. 
Kihlstrom, J. \& Cantor, N. (2004). Social Intelligence. In: STERNBERG, Robert (org). Handbook of Intelligence. (2a ed). Cambrigde: Cambrigde University Press. Recuperado em 15 de janeiro, 2013, de <http://books.google.com.br/books?id=YnBGMpIMfJ0C\&printsec=frontcover\&hl=pt$\mathrm{BR} \&$ source $=\mathrm{gbs} \_g e \_s u m m a r y \_r \& c a d=0 \# \mathrm{v}=$ onepage $\& \mathrm{q} \& \mathrm{f}=\mathrm{false}>$.

Lameira, A. P.; Gawryszewski, L. G. \& Pereira Jr, A. (2013). Neurônios espelho. Recuperado em 19 de janeiro, $2013, \quad$ de <http://www.revistasusp.sibi.usp.br/scielo.php?script=sci_arttext\&pid=S1678$51772006000400007 \& \operatorname{lng}=$ es\&nrm=iso\#nota1>.

Martins, C. B.; Genghini, L. A.; Maccari, E. A. \& Genghini, E. B., (2012). Parâmetros para definições de linhas de pesquisas. In: Durante, D. G. (org.). Pesquisa em Secretariado: cenários, perspectivas e desafios. Passo Fundo: Ed. Universidade de Passo Fundo.

Medeiros, J. B. \& Hernandes, S. (2010). Manual da Secretária: técnicas de trabalho (12a ed.). São Paulo: Atlas.

Neiva, E. G. \& D'Elia, M. E. S. (2009). As novas competências do profissional de secretariado (2a ed.). São Paulo: IOB A. Thompson.

Walker, R. E. \& Foley, J. M. (1973). Social Intelligence: its history and measurement. Recuperado em 21 de janeiro, 2013, de <http://www.amsciepub.com/doi/pdf/10.2466/pr0.1973.33.3.839>.

Wamser, E. (2010). A secretária que faz. Blumenau: Nova Letra.

Revista de Gestão e Secretariado - GeSec, São Paulo, v. 5, n. 2, p 23-48, mai./ago. 2014. 
APÊNDICE - Questionário aplicado à secretária executiva

1) Você poderia fazer um breve relato da sua formação e carreira profissional na área de secretariado?

2) Por quantos anos você trabalhou como secretária em empresas? Foi em empresa particular, pública?

3) Em relação ao modelo de inteligência social de Goleman, o que você poderia dizer a respeito da empatia primordial, que é a capacidade de sentir os sinais emocionais não-verbais das pessoas, isso tem alguma relevância para o profissional de secretariado?

4) O segundo aspecto é a sintonia, que nada mais é do que ouvir com total receptividade, oferecendo total atenção à outra pessoa. Que diferença isso faz para o dia a dia da secretária?

5) Precisão empática é a percepção consciente das intenções de alguém, a capacidade de entender os pensamentos e sentimentos do outro. Você considera essa capacidade um facilitador para secretária ao lidar com as pessoas? Você acha que isso deve ser uma habilidade a ser aprimorada para este profissional?

6) A cognição social, que é a facilidade de transitar nos diversos ambientes mantendo uma postura adequada ao contexto e de ser capaz de entender as normas implícitas que regem as interações, é uma característica que deveria ser prioritária para o secretário?

7) A sincronia, que é a habilidade de ler instantaneamente as dicas não-verbais e agir em concordância a elas, é importante para a secretária-executiva? Em quais situações, por exemplo?

8) Para você, a apresentação pessoal do profissional de secretariado executivo no sentido de causar a impressão adequada, se baseia em quais aspectos? O que é importante para o profissional neste sentido?

9) Influência: de que maneira a secretária deve exercer a sua influência no ambiente em que atua?

Revista de Gestão e Secretariado - GeSec, São Paulo, v. 5, n. 2, p 23-48, mai./ago. 2014. 
Quais atitudes ela deve ter para que possa moldar os resultados das interações sociais?

10) A preocupação da secretária em ajudar, em colocar-se a disposição, deve ser restrita somente ao executivo a quem ela assessora ou com os demais colegas também, independentemente da posição hierárquica? O que você pensa sobre a secretária que só é prestativa ao seu superior direto?

Revista de Gestão e Secretariado - GeSec, São Paulo, v. 5, n. 2, p 23-48, mai./ago. 2014. 